\title{
Individual- and community-level social gradients of edentulousness
}

\author{
Kanade Ito ${ }^{1,2^{*}}$, Jun Aida ${ }^{1}$, Tatsuo Yamamoto ${ }^{3}$, Rika Ohtsuka ${ }^{4}$, Miyo Nakade ${ }^{5}$, Kayo Suzuki ${ }^{6,7}$, Katsunori Kondo ${ }^{6,8}$,
} Ken Osaka ${ }^{1}$ and for the JAGES group

\begin{abstract}
Background: Community-level factors as well as individual-level factors affect individual health. To date, no studies have examined the association between community-level social gradient and edentulousness. The aim of this study was to investigate individual- and community-level social inequalities in edentulousness and to determine any explanatory factors in this association.

Methods: We analyzed the data from the Japan Gerontological Evaluation Study (JAGES). In 2010-2012, 112,123 subjects aged 65 or older responded to the questionnaire survey (response rate $=66.3 \%$ ). Multilevel logistic regression analysis was applied to determine the association between community-level income and edentulousness after accounting for individual-level income and demographic covariates. Then, we estimated the probability of edentulousness by individual- and community-level incomes after adjusted for covariates.

Results: Of 79,563 valid participants, the prevalence of edentulousness among 39,550 men (49.7\%) and 40,013 women (50.3\%) were both 13.8\%. Living in communities with higher mean incomes and having higher individuallevel incomes were significantly associated with a lower risk of edentulousness (odds ratios [ORs] by 10,000 USD increments were 0.37 (95\% confidence interval [Cl] [0.22-0.63]) for community-level and 0.85 (95\% Cl [0.84-0.86]) for individual-level income). Individual- and community-level social factors, including density of dental clinics, partially explained the social gradients. However, in the fully adjusted model, both community- and individual-level social gradients of edentulousness remained significant (ORs $=0.43$ (95\% Cl [0.27-0.67]) and 0.90 (95\% Cl [0.88-0.91]), respectively). One standard deviation changes in community- and individual-level incomes were associated with 0.78 and 0.84 times lower odds of edentulousness, respectively. In addition, compared to men, women living in communities with higher average incomes had a significantly lower risk of edentulousness ( $p$-value for interaction $<0.001$ ).
\end{abstract}

Conclusions: Individual- and community-level social inequalities in dental health were observed. Public health policies should account for social determinants of oral health when reducing oral health inequalities.

Keywords: Dental public health, Edentulous/edentulism, Income inequality, Gender differences, Multilevel analysis

\section{Background}

Severe tooth loss is the 36th most prevalent condition among 291 diseases and it caused a loss of 106 disabilityadjusted life-years per 100,000 population [1]. Prevalence of severe tooth loss increases with age. Approximately $20 \%$ of the older population experienced severe tooth loss

\footnotetext{
* Correspondence: kanade-i@umin.ac.jp

'Department of International and Community Oral Health, Tohoku University Graduate School of Dentistry, Sendai City, Miyagi, Japan

${ }^{2}$ Division of Oral Health Sciences, Department of Health Sciences, School of Health and Social Services, Saitama Prefectural University, Koshigaya City, Saitama, Japan

Full list of author information is available at the end of the article
}

[2]. Severe tooth loss causes chewing difficulties and poor nutritional status [3]. It also affects general health status. For example, tooth loss predicts the onset of future comorbidities such as dementia [4] and mortality [5].

Recent studies showed that the prevalence of severe tooth loss differed by socioeconomic group [6-8]. These health inequalities are caused by social determinants of health and can be observed on social gradients [9]. Adverse social conditions such as lower income and lower educational attainment affect the health of not only the most disadvantaged people, but also the entire population within a society $[10,11]$. The differences in

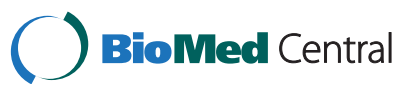

(c) 2015 Ito et al. This is an Open Access article distributed under the terms of the Creative Commons Attribution License (http://creativecommons.org/licenses/by/4.0), which permits unrestricted use, distribution, and reproduction in any medium, provided the original work is properly credited. The Creative Commons Public Domain Dedication waiver (http:// creativecommons.org/publicdomain/zero/1.0/) applies to the data made available in this article, unless otherwise stated. 
social conditions create a stepwise gradient of health conditions between social groups $[12,13]$. The total loss of teeth (i.e., edentulousness) reflects the social determinants of an individual's life-course, as it is the result of oral health behavior, oral diseases, and the community health care system [14]. Reducing oral health inequalities is an urgent matter for both researchers and policymakers [15-17]. Furthermore, determining the factors that affect oral health inequalities is important for future public health interventions.

Recent studies have demonstrated that not only individual factors, but also community-level social determinants such as income inequalities or community-level mean income affect the health of individuals and facilitate health inequalities $[7,8,18]$. Because community factors potentially affect the health of all residents in an area, it is important to understand their effects on health. However, to the best of our knowledge, no study has examined both the individual- and community-level social gradients of edentulousness. Thus, the aims of the present study were: 1) to investigate the association between individual- and community-level incomes and edentulousness, 2) to determine the explanatory factors for edentulousness inequalities, and 3) to investigate gender differences within the socioeconomic inequalities of edentulousness.

\section{Methods}

\section{Data collection}

We used cross-sectional data from the Japan Gerontological Evaluation Study (JAGES) cohort study in Japan. The JAGES project is an ongoing prospective cohort study investigating social and behavioral factors associated with the loss of health related to functional decline or cognitive impairment among individuals aged 65 years or older $[6,19,20]$. Between August 2010 and January 2012, a total of 169,215 community-dwelling people aged 65 years and older were randomly selected from 31 municipalities in 12 prefectures in Japan and mailed a set of questionnaires. In total, 112,123 people in 31 municipalities participated (response rate $=66.3 \%$ ). We used data from 79,563 participants without missing responses.

\section{Outcome variable}

The outcome variable for the present analysis was edentulousness (i.e., edentulous or dentulous). Current dental status was measured by a self-administered questionnaire. Respondents were asked "What is the status of your dental health?" with four choices: 1) I have 20 or more natural teeth, 2) I have 10 to 19 natural teeth, 3) I have 1 to 9 natural teeth, or 4) I have no natural teeth. We categorized answers 1-3 as "dentulous" and answer 4 as "edentulous."

\section{Main predictors}

We used two income variables as the main predictors. The individual-level equivalent household income was obtained and calculated from the questionnaire. The community-level mean income was obtained from national census data [21]. Both income variables were used as continuous variables and the unit used was 10,000 USD (1 USD = $100 \mathrm{JPY})$.

\section{Individual-level socio-demographic covariates}

Sex, age (65-69, 70-74, 75-79, 80-84 and $>84$ years old), marital status (currently married, widowed, divorced, never married, and other), and educational attainment (years of school education received $(<6,6-9,10-12,>12$ years, and other)) were used as individual-level socio-demographic covariates. Marital status [22-24] and educational attainment $[25,26]$ were associated with general and oral health status. In addition, both variables in this study were associated with income level. Therefore we included these variables as covariates.

\section{Community-level socio-demographic covariate}

Density of dental clinics is a proxy for access to dental care in communities. A previous study in Japan indicated that density of dental clinics was an appropriate proxy for access to care [27]. Dental status is associated with access to dental care [27]. Density of dental clinics is likely to be higher in urban areas than rural areas [28]. Generally, urban areas are richer than rural areas [29]. Thus, we used density of dental clinics as a covariate of community-level income in this analysis. Density of dental clinics in each municipality in 2010 were obtained from the census data and used as the community-level variable [30].

\section{Data analysis}

In our dataset, 79,563 individuals (individual-level) were nested across 30 municipalities (community-level). We have hypothesized that oral health is affected not only by individual-level socioeconomic status but also by community-level social conditions. To examine the contextual effect of community-level income on edentulousness, we applied a 2-level multilevel logistic regression analysis with random intercepts and fixed slopes. To determine explanatory factors in the association between individual- and community-level incomes and edentulousness, we built the models as follows. Model 1 tested the association between individual- and community-level incomes and edentulousness. Model 2 tested the association between income variables and edentulousness after adjusting for age, sex, and marital status. Model 3 added educational attainment into Model 2. Model 4 was the fully adjusted model, adding the community-level variable (density of dental clinics) into Model 3. To determine 
gender differences in the effect of both individual- and community-level incomes on dental health, interaction terms were included in the fully adjusted model. To evaluate the degrees of individual- and community-level variances in edentulousness, median odds ratios (ORs) were calculated [31]. To compare the degrees of the association between individual- and community-level income variables and edentulousness, we constructed a fully adjusted model with standardized income variables. When nonstandardized income variables were included into the models, they were grand mean centered. Analysis were conducted using MLwiN version 2.28 (Centre for Multilevel Modelling, University of Bristol, UK).

\section{Ethical considerations}

Ethical approval for the study was obtained from the Ethics Committee at Nihon Fukushi University, Japan (Approval number: 10-05).

\section{Results}

The average ages of 39,550 men (49.7\%) and 40,013 women $(50.3 \%)$ were $73.5(\mathrm{SD}=5.97)$ and $73.7(\mathrm{SD}=6.17)$ years old, respectively. The prevalence of edentulousness was $13.8 \%$ for both men and women. Table 1 shows the demographic distribution of the variables by dental status. Edentulous individuals had significantly lower incomes and lived in communities with lower mean incomes $(\mathrm{p}<0.001)$.

Table 2 shows the results of the multivariate multilevel analysis. In the intercept-only model (not shown), there was a significant difference in edentulousness between municipalities (community-level variance: $\Omega \gamma=$ $0.262, \mathrm{SE}=0.069$ ). The median $\mathrm{OR}$ in the model was 1.629 , which indicated that if a person moved to another municipality with a higher probability of poor dental status, their median risk of edentulousness would increase 1.629 times.

Univariate analyses showed that both individual- and community-level incomes were associated with lower risk for edentulousness; ORs of individual- and communitylevel incomes were 0.84 (95\% confidential interval [CI] [0.84-0.86]) and 0.33 (95\% CI [0.19-0.60]), respectively. Then, we included both income variables into the same model. Having a 10,000 USD higher income and living in a community with a 10,000 USD higher mean income were associated with 0.85 times and 0.37 times lower risk

Table 1 The demographic distribution of variables by dental status $(n=79,563)$

\begin{tabular}{|c|c|c|c|c|}
\hline Categorical variables & & $\begin{array}{c}\text { Dentulousness } \\
\text { n (\%) }\end{array}$ & $\begin{array}{c}\text { Edentulousness } \\
\mathrm{n}(\%)\end{array}$ & $p$-value \\
\hline \multirow[t]{2}{*}{ Sex } & Male & $34,083(86.2)$ & $5,467(13.8)$ & $0.798^{\dagger}$ \\
\hline & Female & $34,507(86.2)$ & $5,506(13.8)$ & \\
\hline \multirow[t]{5}{*}{ Age } & $65-69$ ys & $23,239(94.6)$ & $1,327(5.4)$ & $p<0.001^{\dagger}$ \\
\hline & 70-74 ys & $21,560(90.3)$ & $2,314(9.7)$ & \\
\hline & 75-79 ys & $14,212(83.2)$ & 2,877 (16.8) & \\
\hline & $80-84$ ys & 6,899 (72.8) & $2.573(27.2)$ & \\
\hline & $>84$ ys & $2,680(58.7)$ & $1,882(41.3)$ & \\
\hline \multirow[t]{5}{*}{ Marital status } & Married & $52,769(88.1)$ & $7,115(11.9)$ & $p<0.001^{\dagger}$ \\
\hline & Widowed & $12,185(78.6)$ & $3,311(21.4)$ & \\
\hline & Divorced & $2,007(86.7)$ & $307(13.3)$ & \\
\hline & Never married & $1,316(88.4)$ & $173(11.6)$ & \\
\hline & Other & $313(82.4)$ & $67(17.6)$ & \\
\hline \multirow[t]{5}{*}{ Educational attainment } & $<6$ ys & $1,120(61.70$ & $694(38.3)$ & $p<0.001^{\dagger}$ \\
\hline & $6-9$ ys & $27,979(82.7)$ & $5,853(17.3)$ & \\
\hline & $10-12$ ys & $25,428(89.4)$ & $3,023(10.6)$ & \\
\hline & $>12$ ys & $13,650(91.3)$ & $1,299(8.7)$ & \\
\hline & Other & $413(79.9)$ & $104(20.1)$ & \\
\hline Continuous variables & \multicolumn{4}{|c|}{ Mean (SE) } \\
\hline Density of dental clinics (per 10 thousand population) & & $4.45( \pm 0.837)$ & $4.31( \pm 0.699)$ & $\mathrm{p}<0.001^{\ddagger}$ \\
\hline Individual income (10 thousand US dollars*) & & $2.39( \pm 1.553)$ & $1.95( \pm 1.467)$ & $p<0.001^{\ddagger}$ \\
\hline Community income (10 thousand dollars*) & & $3.18( \pm 0.297)$ & $3.09( \pm 0.285)$ & $p<0.001^{\ddagger}$ \\
\hline
\end{tabular}

${ }^{\dagger} \mathrm{p}$-value for chi-squared test.

${ }^{\ddagger} \mathrm{p}$-value for $t$-test.

*1 US dollar $=100$ Japanese Yen. 
Table 2 Association of edentulousness with individual- and community-level variables determined by multilevel logistic regression $(n=79,563)$

\begin{tabular}{|c|c|c|c|c|c|c|}
\hline & $\begin{array}{c}\text { Model } 1 \\
\text { OR }(95 \% \mathrm{Cl})\end{array}$ & $\begin{array}{c}\text { Model } 2 \\
\text { OR }(95 \% \mathrm{Cl})\end{array}$ & $\begin{array}{c}\text { Model } 3 \\
\text { OR }(95 \% \mathrm{Cl})\end{array}$ & $\begin{array}{c}\text { Model } 4 \\
\text { OR }(95 \% \mathrm{Cl})\end{array}$ & $\begin{array}{c}\text { Model } 5 \\
\text { OR }(95 \% \mathrm{Cl})\end{array}$ & $\begin{array}{c}\text { Model } 6 \\
\text { OR }(95 \% \mathrm{Cl})\end{array}$ \\
\hline \multicolumn{7}{|l|}{ Fixed effect } \\
\hline \multicolumn{7}{|l|}{ Individual-variables } \\
\hline Individual income (10 thousand US dollars) & $0.85(0.84-0.86)$ & $0.87(0.86-0.88)$ & $0.90(0.88-0.91)$ & $0.90(0.88-0.91)$ & $0.90(0.88-0.92)$ & $0.90(0.88-0.91)$ \\
\hline Educational attainment (ref:>12 ys) & & & 1.00 & 1.00 & 1.00 & 1.00 \\
\hline$<6$ ys & & & $2.19(1.94-2.47)$ & $2.19(1.94-2.47)$ & $2.19(1.94-2.47)$ & $2.19(1.93-2.48)$ \\
\hline $6-9$ ys & & & $1.61(1.50-1.73)$ & $1.61(1.51-1.73)$ & $1.62(1.51-1.73)$ & $1.62(1.51-1.73)$ \\
\hline $10-12$ ys & & & $1.15(1.07-1.24)$ & $1.15(1.07-1.24)$ & $1.16(1.08-1.24)$ & $1.16(1.08-1.25)$ \\
\hline Other & & & $1.79(1.41-2.28)$ & $1.80(1.42-2.28)$ & $1.80(1.42-2.28)$ & $1.80(1.42-2.29)$ \\
\hline \multicolumn{7}{|l|}{ Community-variables } \\
\hline Community income (10 thousand US dollars) & $0.37(0.22-0.63)$ & $0.39(0.25-0.61)$ & $0.41(0.27-0.63)$ & $0.43(0.27-0.67)$ & $0.43(0.27-0.67)$ & $0.53(0.33-0.85)$ \\
\hline \multicolumn{2}{|c|}{ Density of dental clinics (per 10 thousand population) } & & & $0.96(0.78-1.19)$ & $0.96(0.78-1.19)$ & $0.96(0.78-1.18)$ \\
\hline Interaction term (Sex*Individual income) & & & & & $0.98(0.95-1.02)$ & \\
\hline Interaction term (Sex*Community income) & & & & & & $0.63(0.54-0.73)$ \\
\hline Random effects (SE) & $0.148(0.039)$ & $0.105(0.028)$ & $0.095(0.026)$ & $0.095(0.026)$ & $0.095(0.026)$ & $0.095(0.026)$ \\
\hline Median OR & 1.443 & 1.362 & 1.342 & 1.342 & 1.342 & 1.342 \\
\hline
\end{tabular}

Model 1: Adjusted for individual- and community-level incomes.

Model 2: Model $1+$ age, sex, and marital status.

Model 3: Model $2+$ educational attainment.

Model 4 (full model): Model $3+$ community-variable (density of dental clinics)

Model 5,6: Model $4+$ each interaction term.

*1 US dollar $=100$ Japanese Yen.

for edentulousness, respectively (Model 1). Individual characteristics mediated these relationships by $13.5 \%$ (individual-level income) and 3.4\% (community-level income), respectively (Model 2, calculated from the ORs [32]). Educational attainment further attenuated the ORs of individual- and community-level income variables by $20.5 \%$ and $3.8 \%$, respectively (Model 3 ). The communitylevel covariate, density of dental clinics, only mediated the association between community-level income and edentulousness (2.1\% reduction of the OR, Model 4$)$. Even after considering all covariates, there remained significant geographical differences and individual- and communitylevel social gradients for edentulousness (Model 4). When standardized income variables were included in Model 4 instead of non-standardized income variables, ORs for individual- and community-level income variables were 0.84 (95\% CI [0.82-0.87]) and 0.78 (95\% CI [0.68$0.89]$ ), respectively. There was a significant interaction between gender and community-level income, although the interaction between gender and individual-level income was non-significant (Models 5 and 6). Compared to men, women living in areas with higher community-level incomes had a lower probability of edentulousness (Figure 1). For individual-level income, similar social gradients were observed among both men and women (Figure 1).

\section{Discussion}

To the best of our knowledge, this study was the first to examine both the individual- and community-level social gradients of edentulousness using a multilevel analysis. This large-scale multilevel analysis demonstrated that not only individual-level income but also communitylevel income showed social gradients for edentulousness. Present study also investigated the factors which associated between income inequalities and dental status. Individual socioeconomic characteristic partially mediated the association between both individual- and community-level incomes and edentulousness. The community's sociodemographic characteristic also partially mediated the association between community-level income and edentulousness. However, even after adjusting for all covariates, individual- and community-level social gradients remained. In addition, compared to men, women living in municipalities with higher community-level incomes derived greater oral health benefits from the social environment.

The present study reports similar result to previous studies using non-oral health outcomes, which have suggested that community-level social factors affect population health [18]. Those systematic review and metaanalysis showed that poor community-level socioeconomic environment increased resident mortality [18]. A metaanalysis of 11 studies with smaller sample sizes indicated 


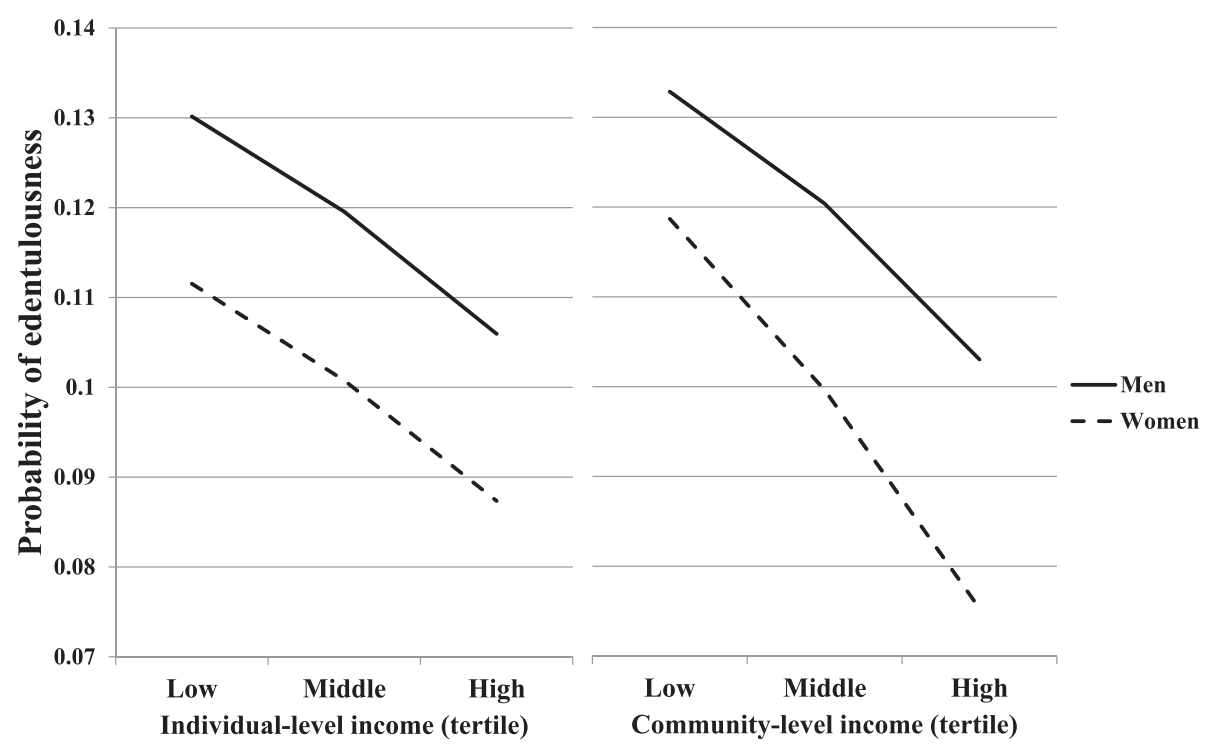

Figure $1 \mathrm{Gender}$ difference in the association between individual- and community-level incomes and probability of edentulousness.

Compared to men, women living in areas with higher community-level incomes had a lower probability of edentulousness.

that living in areas with low socioeconomic status increased mortality 1.11 times compared to areas with high socioeconomic status [18]. Another meta-analysis of seven studies with larger sample sizes also demonstrated that living in low socioeconomic status areas increased mortality 1.07 times [18]. In oral health studies, regardless of individual-level income, adults living in affluent areas had a higher number of remaining teeth than those living in deprived areas, after adjusting for age, sex, and educational attainment [8]. Dental health is considered to be affected to a greater extent by community-level factors. Previous studies conducted in one Japanese prefecture reported larger geographical differences in the dental outcome of number of remaining teeth compared to self-rated health [7]. Therefore, a public health intervention considering community-level social determinants would be more effective.

There are at least three possible pathways between community-level income and oral health. First, access to dental care could explain the mechanism. Second, individual health behaviors are formed by the surrounding environment. Third, people living in affluent communities are less likely to have psychosocial stress than those living in deprived communities. In relation to the first pathway, although we considered access to dental clinics in the models, there might be unexplained variance of the outcome associated with access to dental care. A previous study demonstrated that low-income individuals had less access to dental clinics than high-income individuals [33]. Moreover, access to dental clinics was significantly associated with area-level income after adjusting individual income [28]. This study suggested that people living in affluent areas were more likely to visit a dental clinic than those in deprived areas, regardless of individual socioeconomic status. Although the variable we used, density of dental clinics, could change throughout the lifecourse of each respondent, we could not consider possible changes in this variable. Therefore, this might have caused the unexplained variance of the outcome, which was associated with access to dental care. For the second pathway, compared to deprived communities, affluent communities tend to have positive social environments, including sufficient grocery stores with fresh and healthy food, public safety, and good access to hospitals and dental clinics $[34,35]$. People living in affluent communities tend to eat more fruits and sugar-free foods because they can easily purchase healthy foods at grocery stores in their communities [36,37]. In addition, people living in affluent communities are also more likely to drink healthy beverages, such as non-sugared teas rather than sodas [38]. Sugar is an established risk of dental caries [39]. Moreover, recent study also indicated that sugar associated with risk of periodontal diseases [40]. Healthy lifestyles can help prevent them. For the third pathway, people living in affluent communities are less likely to have psychosocial stress because of increased safety, good social capital (e.g., social connections and social networks), and social norms than those living in deprived communities [41]. Psychosocial stress is also associated with smoking status, which affects periodontal diseases causing tooth loss [42]. In addition, community public safety affects oral health by reducing the possibility of dental injuries. Dental injury was affected by community social environment [43]. 
Present study showed that community explanatory variable partially mediated the association between community-level income and edentulousness. To examine the possibility of the pathway "access to dental care", we include the variable into the model. However, variable on access to dental care explained only $2.1 \%$ of the association between community-level income and edentulousness. Further studies that consider the wider range of variables related to the pathway, such as social capital and geographical clustering of dental health behaviors, are needed.

In the present study, women's dental health was affected by community-level income to a greater extent than men's health. Previous studies on other health outcomes have reported similar results. Compared to men, the self-rated health of women is considered to be affected to a greater extent by the neighborhood social environment [44]. Another study on self-rated health reported similar findings and the authors suggested that this might be because women tend to spend more time at home and in the community [45]. Thus, women were more likely than men to communicate with neighbors. Therefore, women's health behaviors are more likely to be affected by neighbors though informal social control and social influence. A previous study in Japan demonstrated that, for older women, the distance to a dental clinic was an important factor for dental attendance, while distance was not significantly associated with access to dental care among older men [27]. Because many older women in Japan do not have a driver's license, public transportation is considered an important factor for dental clinic access [27].

\section{Public health implications}

Community factors are important because they potentially affect the health of all residents in a given area. The present study revealed the importance of community-level socioeconomic status on oral health. Therefore, interventions should focus not only on individual efforts but also consider community-level social determinants underlying the oral health of a population. Therefore, after relevant factors are determined by future studies, upstream approaches including structural and environmental interventions for improving various social determinants of communities (e.g., smoking policies for public spaces, food policies for reducing sugar consumption, health care system reforms for improving access to preventive and curative care, and access to fluoride in the water system or in schools) are necessary for reducing oral health inequalities [46-48]. In addition to these upstream approaches, building society which focuses on not only economic growth, but also fair distribution of well-being of individuals are required [34]. As various socioeconomic environment of community affect health of residents, broader social and economic policies should consider health and well-being of residents [34].

\section{Limitation and strengths}

This study has some limitations. First, this was a crosssectional study; thus, we cannot rule out the possibility of reverse causation. Consequently, prospective followup studies are required. Second, though the validity of self-reporting number of remaining teeth was validated, measurements were obtained from a self-administered questionnaire [49]. If we can obtain clinical measurements of remaining teeth, which are more accurate than self-administered questionnaires, the association between income variables and edentulousness will be strengthened. Third, there might have a potential bias because of a lack of many cases. The main strength of this study was its large sample size. In addition, our survey was conducted across an adequate number of municipalities with various characteristics and we used appropriate statistical analysis. Therefore, the present study could legitimately describe the effects of community factors.

\section{Conclusion}

In conclusion, community-level income, as well as individual-level income, formed social gradients for edentulousness, even after accounting for individualand community-level factors. The oral health of women living in municipalities with higher community-level incomes benefited from the social environment.

\section{Availability of supporting data}

Raw data is available from corresponding author.

\section{Standards of reporting}

This study was prepared according to STROBE check list for cross-sectional studies.

\section{Consent}

Present study was an observational study and not using human biological specimens. We explained all relevant details regarding the study to be carried out and provide each prospective subject an opportunity to refuse inclusion in the research. Subject who consented to participate in the study wrote the self-reported questionnaire and send it by mail.

\section{Abbreviations}

JAGES: Japan Gerontological Evaluation Study; OR: Odds ratio; Cl: Confidence interval.

\section{Competing interests}

The authors declare that they have no competing interests. 


\section{Authors' contributions}

$\mathrm{KI}$ participated in the acquired the data and the study design, performed the statistical analysis, and drafted the manuscript as the principal author. JA helped to develop the idea of the study, participated in the acquired the data, advised the statistical analysis, and edited the manuscript. TY participated in the acquired the data and the study design, and edited the manuscript. RO and MN participated in the acquired the data and reviewed the manuscript. KS helped to edit the manuscript, participated in its design, and advised the statistical analysis. KK is the principal investigator of the JAGES project, helped to develop the idea of the study, participated in the acquired the data and the study design, and edited the manuscript. $\mathrm{KO}$ participated in the acquired the data, helped with data analysis, and critically revised the manuscript. All authors read and approved the final manuscript.

\section{Acknowledgments}

This study used data obtained from the Japan Gerontological Evaluation Study (JAGES), conducted by the Nihon Fukushi University Center for Well-Being and Society as one of their research projects. This study was supported in part by Grants-in-Aid for Scientific Research (A) (KAKENHI 23243070), (B) (22390400 and 24390469), and (C) (22592327) from the Japan Society for the Promotion of Science. The study was also supported by a Health and Labour Sciences Research Grant, and grants for Comprehensive Research on Aging and Health (H24-Choju-Wakate-009) and Comprehensive Research on Lifestyle-Related Diseases including Cardiovascular Diseases and Diabetes Mellitus (H24-Junkanki [Seishu]-Ippan-007) from the Ministry of Health, Labour and Welfare (MHLW), Japan. The sponsors of the study had no role in the study design, data collection, data analysis, data interpretation, or writing of the paper.

\section{Author details}

${ }^{1}$ Department of International and Community Oral Health, Tohoku University Graduate School of Dentistry, Sendai City, Miyagi, Japan. ${ }^{2}$ Division of Oral Health Sciences, Department of Health Sciences, School of Health and Social Services, Saitama Prefectural University, Koshigaya City, Saitama, Japan. ${ }^{3}$ Department of Dental Sociology, Graduate School of Dentistry, Kanagawa Dental University, Yokosuka City, Kanagawa, Japan. ${ }^{4}$ Research Team for Human Care, Tokyo Metropolitan Institute of Gerontology, Itabashi Ward, Tokyo, Japan. ${ }^{5}$ Department of Nutrition, Faculty of Health and Nutrition, Tokaigakuen University, Nagoya City, Aichi, Japan. ${ }^{6}$ Center for Well-being and Society, Nihon Fukushi University, Nagoya City, Aichi, Japan. ${ }^{7}$ Department of Policy Studies, Aichi Gakuin University, Nisshin City, Aichi, Japan. ${ }^{8}$ Center for Preventive Medical Sciences, Chiba University, Chiba City, Chiba, Japan.

\section{Received: 12 December 2014 Accepted: 20 February 2015} Published online: 11 March 2015

\section{References}

1. Marcenes W, Kassebaum NJ, Bernabe E, Flaxman A, Naghavi M, Lopez A, et al. Global burden of oral conditions in 1990-2010: a systematic analysis. J Dent Res. 2013;92(7):592-7.

2. Kassebaum NJ, Bernabe E, Dahiya M, Bhandari B, Murray CJ, Marcenes W. Global Burden of Severe Periodontitis in 1990-2010: A Systematic Review and Meta-regression. J Dent Res. 2014;93(11):1045-53.

3. Sheiham A, Steele JG, Marcenes W, Lowe C, Finch S, Bates CJ, et al. The relationship among dental status, nutrient intake, and nutritional status in older people. J Dent Res. 2001;80(2):408-13.

4. Yamamoto T, Kondo K, Hirai H, Nakade M, Aida J, Hirata Y. Association between self-reported dental health status and onset of dementia: a 4-year prospective cohort study of older Japanese adults from the Aichi Gerontological Evaluation Study (AGES) Project. Psychosom Med. 2012;74(3):241-8

5. Aida J, Kondo K, Yamamoto T, Hirai H, Nakade M, Osaka K, et al. Oral health and cancer, cardiovascular, and respiratory mortality of Japanese. J Dent Res. 2011;90(9):1129-35.

6. Matsuyama Y, Aida J, Takeuchi K, Tsakos G, Watt RG, Kondo K, et al. Inequalities of dental prosthesis use under universal healthcare insurance. Community Dent Oral Epidemiol. 2013;42(2):122-8.

7. Aida J, Kondo K, Kondo N, Watt RG, Sheiham A, Tsakos G. Income inequality, social capital and self-rated health and dental status in older Japanese. Soc Sci Med. 2011;73(10):1561-8.
8. Sanders AE, Turrell G, Slade GD. Affluent neighborhoods reduce excess risk of tooth loss among the poor. J Dent Res. 2008;87(10):969-73.

9. Watt RG, Sheiham A. Integrating the common risk factor approach into a social determinants framework. Community Dent Oral Epidemiol. 2012;40(4):289-96.

10. Kawachi I, Kennedy BP. Income inequality and health: pathways and mechanisms. Health Serv Res. 1999;34(1 Pt 2):215-27.

11. Coogan PE, Wise LA, Cozier YC, Palmer JR, Rosenberg L. Lifecourse educational status in relation to weight gain in African American women. Ethn Dis. 2012;22(2):198-206.

12. Brennan SL, Holloway KL, Williams LJ, Kotowicz MA, Bucki-Smith G, Moloney DJ, et al. The social gradient of fractures at any skeletal site in men and women: data from the Geelong Osteoporosis Study Fracture Grid. Osteoporos Int. 2015. doi:10.1007/s00198-014-3004-y.

13. Nguyen AB, Moser R, Chou WY. Race and health profiles in the United States: an examination of the social gradient through the 2009 CHIS adult survey. Public Health. 2014;128(12):1076-86.

14. Astrom AN, Ekback G, Lie SA, Ordell S. Life-course social influences on tooth loss and oral attitudes among older people: evidence from a prospective cohort study. Eur J Oral Sci. 2015;123(1):30-8.

15. Sgan-Cohen HD, Evans RW, Whelton H, Villena RS, MacDougall M, Williams DM. IADR Global Oral Health Inequalities Research Agenda (IADRGOHIRA(R)): a call to action. J Dent Res. 2013;92(3):209-11.

16. Williams DM. Global oral health inequalities: the research agenda. J Dent Res. 2011;90(5):549-51.

17. Marmot M, Friel S, Bell R, Houweling TA, Taylor S. Closing the gap in a generation: health equity through action on the social determinants of health. Lancet. 2008;372(9650):1661-9.

18. Meijer M, Rohl J, Bloomfield K, Grittner U. Do neighborhoods affect individual mortality? A systematic review and meta-analysis of multilevel studies. Soc Sci Med. 2012;74(8):1204-12.

19. Takeuchi K, Aida J, Kondo K, Osaka K. Social participation and dental health status among older Japanese adults: a population-based cross-sectional study. PLoS One. 2013;8(4):e61741.

20. Yamamoto T, Kondo K, Aida J, Fuchida S, Hirata Y. Association between the longest job and oral health: Japan Gerontological Evaluation Study project cross-sectional study. BMC Oral Health. 2014;14:130

21. Ministry of Internal Affairs and Communications. Status Survey of Tax on Municipalities. The System of Social and Demographic Statistics of Japan, Basic data of Shi, Ku, Machi, Mura by Statistics Bureau, Ministry of Internal Affairs and Communications. 2010.

22. Fukuda Y, Hiyoshi A. Associations of household expenditure and marital status with cardiovascular risk factors in Japanese adults: analysis of nationally representative surveys. J Epidemiol. 2013;23(1):21-7.

23. Evans TG. Socioeconomic consequences of blinding onchocerciasis in west Africa. Bull World Health Organ. 1995;73(4):495-506.

24. Wennstrom A, Ahlqwist M, Stenman U, Bjorkelund C, Hakeberg M. Trends in tooth loss in relation to socio-economic status among Swedish women, aged 38 and 50 years: repeated cross-sectional surveys 1968-2004. BMC Oral Health. 2013;13:63.

25. Natto ZS, Aladmawy M, Alasqah M, Papas A. Factors contributing to tooth loss among the elderly: A cross sectional study. Singapore Dent J. 2014;35:17-22.

26. Sabbah W, Tsakos G, Chandola T, Sheiham A, Watt RG. Social gradients in oral and general health. J Dent Res. 2007;86(10):992-6.

27. Hanibuchi T, Aida J, Nakade M, Hirai H, Kondo K. Geographical accessibility to dental care in the Japanese elderly. Community Dent Health. 2011;28(2):128-35.

28. Lupi-Pegurier L, Clerc-Urmes I, Abu-Zaineh M, Paraponaris A, Ventelou B. Density of dental practitioners and access to dental care for the elderly: a multilevel analysis with a view on socio-economic inequality. Health Policy. 2011;103(2-3):160-7.

29. Yun WJ, Rhee JA, Kim SA, Kweon SS, Lee YH, Ryu SY, et al. Household and area income levels are associated with smoking status in the Korean adult population. BMC Public Health. 2015;15(1):39.

30. Ministry of Health, Labour and Welfare. Survey of Medical Institutions. The System of Social and Demographic Statistics of Japan, Basic data of Shi, Ku, Machi, Mura by Statistics Bureau, Ministry of Internal Affairs and Communications. 2010. 
31. Merlo J, Chaix B, Yang M, Lynch J, Rastam L. A brief conceptual tutorial on multilevel analysis in social epidemiology: interpreting neighbourhood differences and the effect of neighbourhood characteristics on individual health. J Epidemiol Community Health. 2005;59(12):1022-8.

32. Schempf AH, Kaufman JS. On the percent of excess risk explained. J Epidemiol Community Health. 2011;65(2):190.

33. Al-Haboubi M, Klass C, Jones K, Bernabe E, Gallagher JE. Inequalities in the use of dental services among adults in inner South East London. Eur J Oral Sci. 2013;121(3 Pt 1):176-81.

34. Marmot M, Bell R. Fair society, healthy lives. Public Health. 2012;126 Suppl 1:S4-10.

35. Cummins S, Stafford M, Macintyre S, Marmot M, Ellaway A. Neighbourhood environment and its association with self rated health: evidence from Scotland and England. J Epidemiol Community Health. 2005;59(3):207-13.

36. Morland K, Wing S, Diez Roux A, Poole C. Neighborhood characteristics associated with the location of food stores and food service places. Am J Prev Med. 2002;22(1):23-9.

37. Turrell G, Bentley R, Thomas LR, Jolley D, Subramanian S, Kavanagh AM. A multilevel study of area socio-economic status and food purchasing behaviour. Public Health Nutr. 2009;12(11):2074-83.

38. Forsyth A, Macintyre S, Anderson A. Diets for disease? Intraurban variation in reported food consumption in Glasgow. Appetite. 1994;22(3):259-74.

39. Moynihan PJ, Kelly SA. Effect on caries of restricting sugars intake: systematic review to inform WHO guidelines. J Dent Res. 2014;93(1):8-18.

40. Lula EC, Ribeiro CC, Hugo FN, Alves CM, Silva AA. Added sugars and periodontal disease in young adults: an analysis of NHANES III data. Am J Clin Nutr. 2014;100(4):1182-7.

41. Diez Roux AV, Mair C. Neighborhoods and health. Ann N Y Acad Sci. 2010;1186:125-45.

42. Chiou LJ, Yang YH, Hung HC, Tsai CC, Shieh TY, Wu YM, et al. The association of psychosocial factors and smoking with periodontal health in a community population. J Periodontal Res. 2010;45(1):16-22.

43. Pattussi MP, Hardy R, Sheiham A. Neighborhood social capital and dental injuries in Brazilian adolescents. Am J Public Health. 2006;96(8):1462-8.

44. Stafford M, Cummins S, Macintyre S, Ellaway A, Marmot M. Gender differences in the associations between health and neighbourhood environment. Soc Sci Med. 2005;60(8):1681-92.

45. Kavanagh AM, Bentley R, Turrell G, Broom DH, Subramanian SV. Does gender modify associations between self rated health and the social and economic characteristics of local environments? J Epidemiol Community Health. 2006;60(6):490-5.

46. Riley JC, Lennon MA, Ellwood RP. The effect of water fluoridation and social inequalities on dental caries in 5-year-old children. Int J Epidemiol. 1999;28(2):300-5.

47. Watt RG. Social determinants of oral health inequalities: implications for action. Community Dent Oral Epidemiol. 2012;40 Suppl 2:44-8.

48. Woodward A, Kawachi I. Why reduce health inequalities? J Epidemiol Community Health. 2000;54(12):923-9.

49. Yamamoto T, Kondo K, Fuchida S, Aida J, Nakade M, Hirata Y. Validity of self-reported oral health variables: Aichi Gerontological Evaluation Study (AGES) project. Health Sci Health Care. 2012;12:4-12.

\section{Submit your next manuscript to BioMed Central and take full advantage of:}

- Convenient online submission

- Thorough peer review

- No space constraints or color figure charges

- Immediate publication on acceptance

- Inclusion in PubMed, CAS, Scopus and Google Scholar

- Research which is freely available for redistribution 